\title{
Emergency separation of craniopagus twins: case report
}

\author{
Farideh Nejat, MD, MPH, ${ }^{1}$ Zohreh Habibi, MD, ${ }^{1}$ Mehrdad Goudarzi, MD, ${ }^{2}$ Mahdi Souraki Azad, MD, ${ }^{3}$ \\ Ehsan Moradi, MD, ${ }^{1}$ Vahid Heidari, MD, ${ }^{1}$ Maliheh Kadivar, MD, ${ }^{4}$ Zahra Ebrahim Soltani, MD, ${ }^{1}$ and \\ Leila Kouchakzadeh, MD5
}

\begin{abstract}
Departments of ${ }^{1}$ Neurosurgery, ${ }^{2}$ Anesthesiology, ${ }^{4}$ Neonatology, and ${ }^{5}$ Pediatrics, Children's Medical Center, Tehran University of Medical Science; and ${ }^{3}$ Sina Hospital, Tehran University of Medical Science, Tehran, Iran

Craniopagus is a very rare congenital anomaly that tends to affect females more often than males. It is classified as partial or total. Most affected twins are either stillborn or die during the perinatal period. Those who survive birth should undergo detailed radiological evaluations soon after their condition becomes stable so that the precise anatomy of the conjoined part can be defined and surgery can be planned in detail by a multidisciplinary team. Recommendations for decreasing the risk of unsuccessful surgery include performing surgery on an elective basis after extensive preoperative radiological evaluations as well as when the twins are at an acceptable age and weight for a complex surgical separation, generally as staged procedures. In addition, the operation should be performed by a well-equipped expert multidisciplinary team.
\end{abstract}

When one of the conjoined twins dies, however, surgical separation cannot be postponed because the shared circulatory system predisposes the alive child to life-threatening complications, including coagulopathy. The authors report on the successful separation of craniopagus twins performed on an emergency basis at 32 weeks of gestational age because of the sudden death of one of them. At the time of separation surgery, the twins each weighed $1250 \mathrm{~g}$. To the best of the authors' knowledge, this is the youngest age and lowest weight yet reported for successful surgical separation. The surviving twin developed a pseudomeningocele, which required a second operation and placement of a cystoperitoneal shunt 4 months after the operation. Additional surgery is planned to repair a cranial defect that resulted from the pseudomeningocele, but his general physical and mental condition was otherwise good at latest follow-up (12 months after separation surgery).

https://thejns.org/doi/abs/10.3171/2017.1.PEDS16306

KEY WORDS craniopagus twins; separation; elective surgery; emergency surgery; congenital

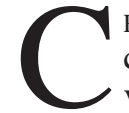
RANIOPAGUS represents one of the rarest and most complex anomalies in pediatric neurosurgery. Survival depends on the type and extent of joining and the presence or absence of associated anomalies. The greatest risks to conjoined twins are related to anesthesia and surgical intervention. ${ }^{2,17}$ One of the most important and terrifying issues for the parents, the medical team, and especially for twins who undergo separation surgery at an older age is the death of one of the twins, which can predispose the other one to death from disseminated coagulopathy, electrolyte disturbance, and systemic infection. ${ }^{11}$

Surgical separation of craniopagus twins is often performed on an elective basis and only after extensive preparation, which includes examination of the twins with different imaging protocols as well as the development of a multidisciplinary team and several conferences that involve members of all disciplines involved in the separation and management of twins. Participants in these conferences include specialists in neurosurgery, plastic surgery, vascular surgery, craniofacial surgery, neonatology, medical imaging, anesthesiology, ethics, and rehabilitation service as well as intensivists. Finally, there is at least one case conference between the executive team and the parents. Only afterward surgery is scheduled to separate the twins.

It is not usual to separate craniopagus twins in an emergency setting, but when one of the twins dies, surgery must be performed as soon as possible, precluding the possibility of extensive radiological investigations and case conferences. Any nonelective surgical separation procedure in craniopagus twins is associated with increased morbidity. ${ }^{11}$

ABBREVIATIONS MCA = middle cerebral artery; $\mathrm{NICU}=$ neonatal intensive care unit. ACCOMPANYING EDITORIAL See pp 305-306. DOI: 10.3171/2017.3.PEDS1719.

SUBMITTED May 27, 2016. ACCEPTED January 13, 2017.

INCLUDE WHEN CITING Published online July 14, 2017; DOI: 10.3171/2017.1.PEDS16306. 
Here, we report a case of craniopagus in which separation was performed on an emergency basis due to the sudden death of one twin. The advantages and disadvantages of this kind of surgery are described. To the best of our knowledge no case of separation of craniopagus twins this young or small has been previously reported.

\section{Case Report}

These twins were born through cesarean section to nonconsanguineous parents in a local hospital in a city far from our center. Prenatal ultrasound examination confirmed a twin pregnancy without any report of craniopagus. The twins were the product of the fifth gestation of a healthy 32-year-old mother and were born prematurely at a gestational age of 28 weeks due to premature membrane rupture. They were boys with a weight of around $700 \mathrm{~g}$ each.

The newborn twins were admitted to the neonatal intensive care unit (NICU) to gain weight and develop independent oral feeding ability. At the postnatal age of 28 days the right-side neonate developed sudden cyanosis and was resuscitated once but developed repeated apnea followed by cardiac arrest. Cardiopulmonary resuscitation was unsuccessful, and the child died 8 hours after the onset of cyanosis.

The twins were referred to Children's Medical Center in Tehran and admitted to the NICU. During transfer the left twin was intubated but breathing on his own (without mechanical ventilation) and had stable hemodynamic status.

The 2 neonates were attached to each other as a partial craniopagus angular frontal type.$^{15}$ The right twin had a cleft lip and palate, was in a lateral to slightly prone position, and was attached to the left twin at the frontal area. He had been dead for 12 hours at the time of presentation at our hospital. The left twin was attached to the right one in supine condition only slightly rotated to the right from his lateral frontal region and had no other abnormalities (Fig. 1, the living twin is marked as the left twin).

On admission to our center, the dead twin was cyanotic in all parts of his body except for the scalp around the attached area. The left twin weighted $1250 \mathrm{~g}$ and had spontaneous respiration with active movement of all 4 limbs in response to stimulation. The results of his laboratory studies were in the normal range with the exception of his hemoglobin level, which was $9 \mathrm{mg} / \mathrm{dl}$. Blood transfusion had been initiated during transfer to our center. The twins had undergone brain MRI at the age of 1 week. This study showed good brain configuration for the left twin but mild ventriculomegaly associated with deformed abnormal brain in the right twin. It seemed to us that the 2 infants had independent major dural sinus systems. The 2 brains were attached to each other in the frontoparietal regions, being intermingled together without an obvious demarcation in some areas (Fig. 2).

Cerebral angiography was not performed because of the very low weight of the living twin. Moreover, the surgical team decided not to go through the vascular system of the living twin but instead used some brain tissue of the dead child to protect the brain and vascular system of the living child from any damage during separation.
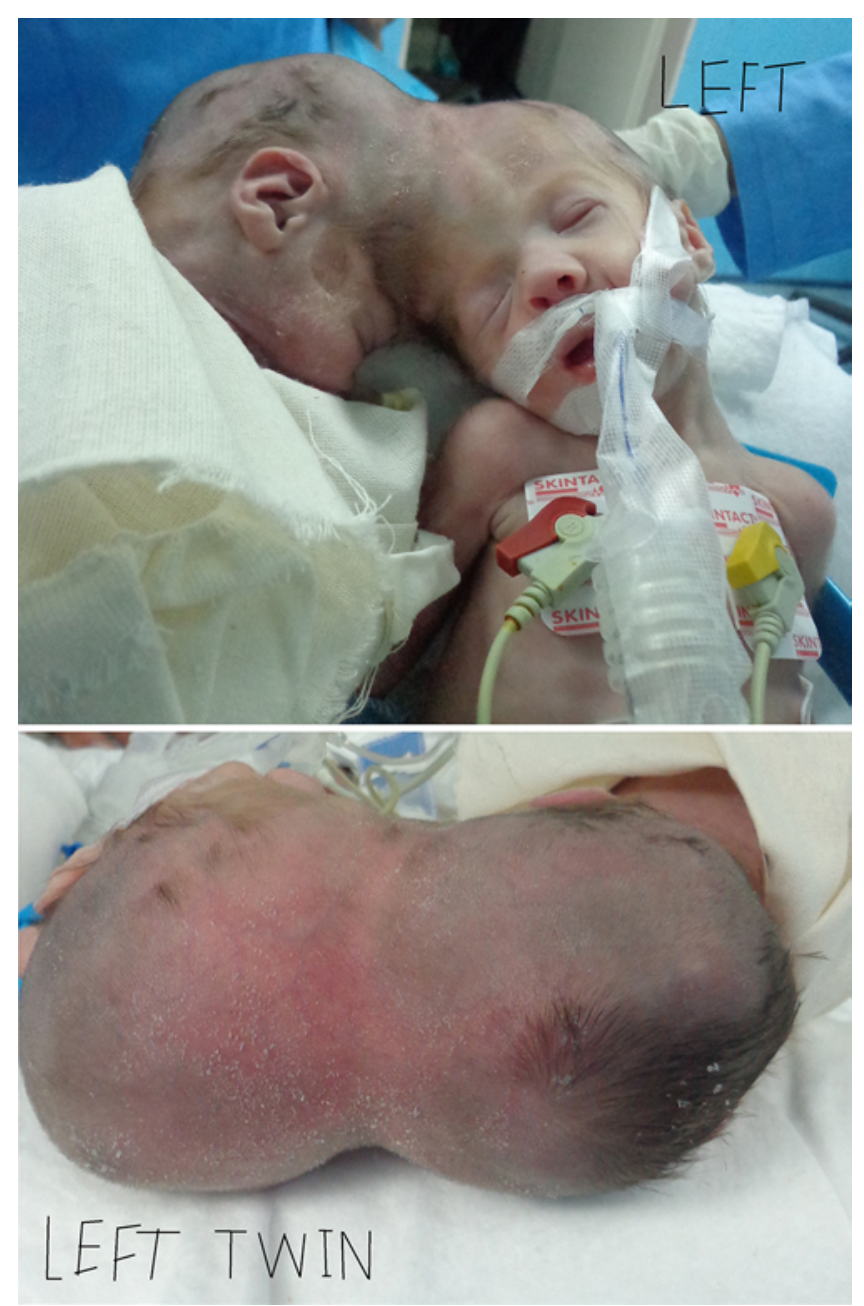

FIG. 1. Photographs of twins showing the extensive area of attachment and classification of their condition as partial craniopagus angular frontal type. The living twin is described in this paper as the left twin, as shown here in a frontal view (upper) and a view of the vertex (lower). Figure is available in color online only.

Due to the risk of coagulopathy and other metabolic and medical problems related to attachment to a dead body, surgical separation was considered as an emergency surgery, and the twins were transferred to the operating room after a brain CT scan was performed (with and without contrast). The CT scan confirmed common venous and arterial branches at the place of attachment. The right twin's brain obviously had a blood supply from the left side, probably from anastomosis between branches of his left middle cerebral artery (MCA) and the living twin's right MCA branches. After injection of contrast medium into the left twin, the right (dead) twin's venous drainage became obviously bright with blood flow that could be followed to the his left jugular vein (Fig. 3).

Meticulous preparation was necessary to decrease the risk of infection. The twins were prepared and draped in such a way as to allow access to the deep and inferior (basal) part of the conjoined segment. The separation procedure was performed in anatomical layers. The skin was incised on the dead side on the scalp about $3 \mathrm{~cm}$ from 


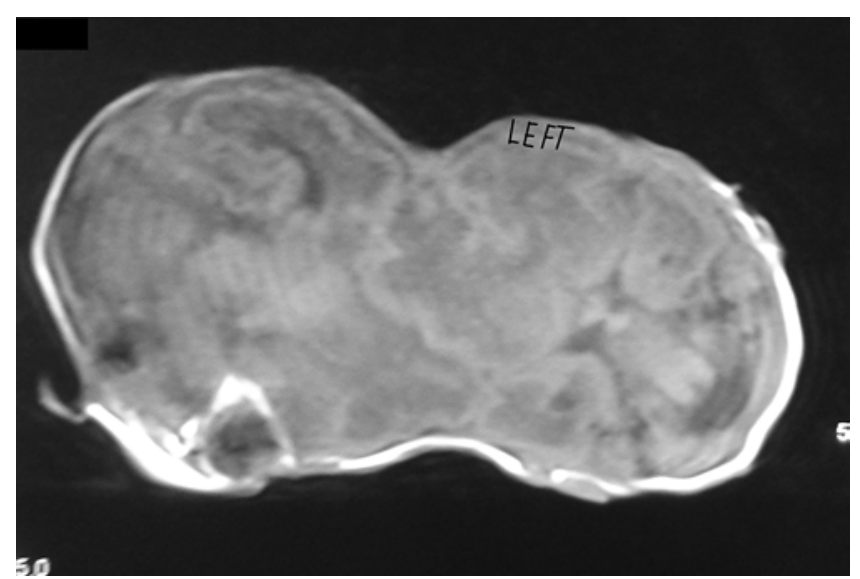

FIG. 2. Axial T1-weighted MR image obtained at the age of 1 week showing relatively normal brain in the left twin but mild ventriculomegaly associated with a deformed and grossly abnormal brain in the right twin. The 2 brains are intermingled in some areas.

the conjoined line on the pink skin to save more skin for closure. Initially the skin was dissected thoroughly in such a way that the twins became separated in the skin plane. Then a craniotomy was performed under the same skin incision, and frontal and parietal bone flaps of the right twin were removed to reach to the border of the 2 skulls (see 3D CT, Fig. 3 left). The most difficult part of separation of the skull was at the base where the bone was very thick and the bleeding was more than what was considered an acceptable amount for a baby weighing $1250 \mathrm{~g}$, although it was rapidly controlled with bone wax (Fig. 4).

The dura mater was opened under the same skin incision. The most difficult part of separation of the dura was again at the base, where it contained several venous structures passing between 2 crania and causing severe bleeding, which was controlled with Surgicel (Ethicon) and coagulation. After full hemostasis was achieved in the bone and dura, brain separation was started with microscissors and suction cauterization. The joined brains were very intermingled according to MRI, so to save the right side of the brain of the living twin, the separation was performed just near the border of both pial surfaces at the expense of the necrotic brain of the right (deceased) twin.
With this approach any damage to the left twin's brain was avoided. The right brain was necrotic in most parts and was evacuated near to the pial border (Fig. 4). In full hemostasis, the dura was closed with dural graft harvested from the pericranium and dura of the dead twin.

A bone flap was not placed over this new dural closure in order to decrease the risk of any pressure on the overlying skin. The skin was closed without any tension. The neonate received a transfusion of $25 \mathrm{ml}$ of isogroup packed red blood cells during the operation. The surgery was performed as rapidly as possible, taking only around 3.5 hours, to decrease the potential risks of massive transfusion and blood loss caused by blood oozing from the exposed skin, skull, dura, and brain.

The deceased twin had a large skin defect at the attachment site that was closed by suturing a piece of glove. Then the infant was dressed by the operating room staff and given to the parents, according to official rules, to be buried and to allow them the opportunity to grieve.

The patient's early postoperative course was uneventful, and he was extubated on the 5th postoperative day. He had satisfactory weight gain, learned to breastfeed, and was discharged from the hospital 1 month after the separation operation with a weight of $2300 \mathrm{~g}$.

During the next 3-4 weeks, he gradually developed a soft tissue collection resembling a large meningocele under the skin flap (Fig. 5 A and B). A CT scan was performed and revealed a cystic change of the right-side twin's residual brain plus ex vacuo ventriculomegaly of the patient's own right lateral ventricle, which extended to the bulging segment. The postoperative CT scan confirmed that the 2 brains were separated from each other with intact pial surfaces in some areas and were fused together without an obvious pial border in other places (Fig. 5 C). Initially, the collection was treated with repeated percutaneous puncture and CSF removal, but it continued to increase in size, and at 4 months of age, the infant underwent a second operation to decrease the height of his head caused by the bulging pseudomeningocele. A cystoperitoneal shunt was placed, and the infant was discharged in good condition after 3 days. As of this writing, 12 months after separation, the surviving twin is in good general physical and mental condition but has some cranial deformity at the site

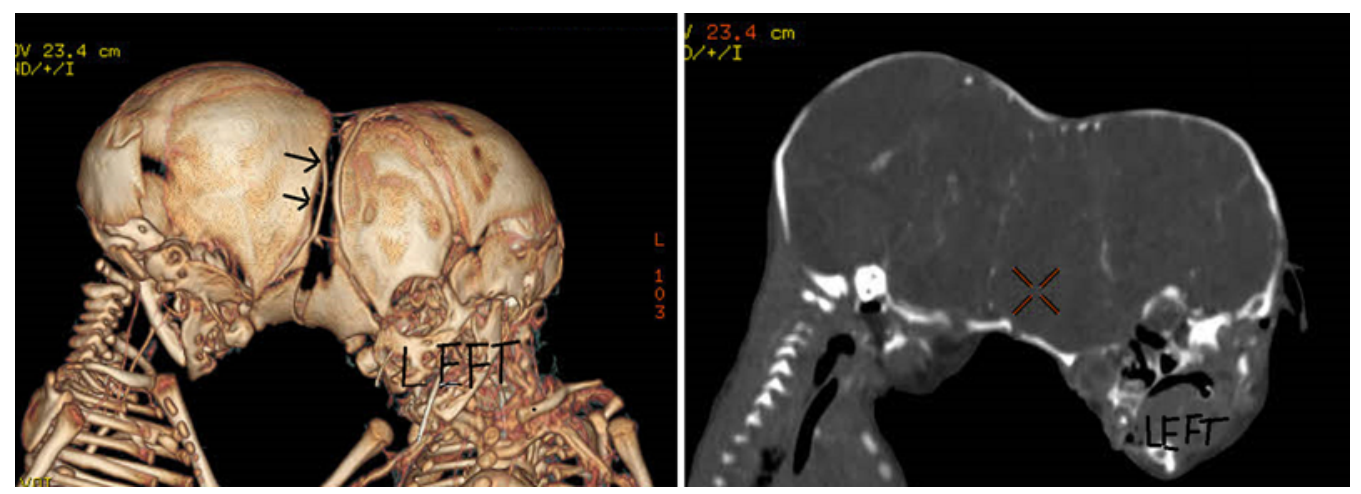

FIG. 3. Left: 3D CT reconstruction showing the 2 skulls and their attachment, resembling a fibrous suture (arrows). Right: Postcontrast CT image showing common venous and arterial branches between the 2 brains. Despite the death of the right twin, contrast traversed from the left twin's brain to the right twin through common venous drainage. Figure is available in color online only. 


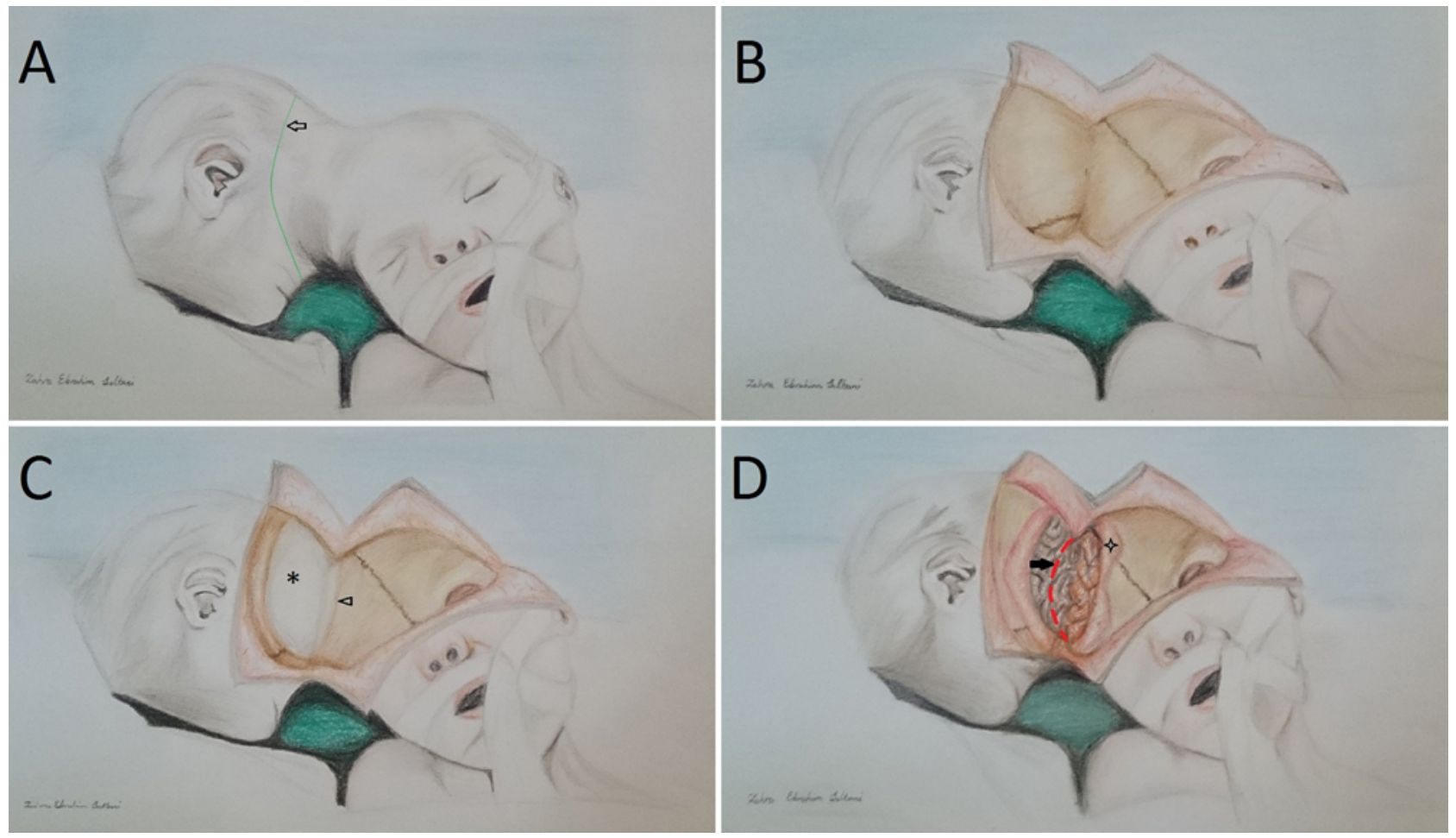

FIG. 4. Sequential illustrations of the operative procedure. A: The initial skin incision (arrow), which was performed on the pink scalp of the dead twin. This allowed skin from this area to be used for closure after separation. B: The underlying skull after dissection of the skin flap. There was a suture-like space between the 2 skulls at the shared area. C: The craniotomy. The edge of the craniotomy on the living twin's side is marked with an arrowhead. The asterisk indicates the dura mater. D: Dural opening (star) and the incision (arrow) of the brain. The living brain was left intact, and the incision passed through only the right twin's brain. Copyright Zahra Ebrahim Soltani. Published with permission. Figure is available in color online only.

of the previous pseudomeningocele, with bone defect and a feature of secondary craniosynostosis that will require cranial reconstruction when he is older and his weight has increased.

\section{Discussion}

Conjoined twins are rare, present in 10-20 per million births, and craniopagus is the rarest type, with an incidence rate of 0.6 per million live births. Conjoined twins are identical twins and are more often female than male. ${ }^{2,3}$ Most craniopagus twins do not survive the perinatal period and are either stillborn or die soon after birth as a result of associated anomalies. ${ }^{2,4,8}$ The current literature does not support any association between the occurrence of craniopagus and maternal age, parity, race, or genetic or environmental factors. ${ }^{2,15}$

Conjoining occurs subsequent to imperfect fission of a single embryo. Craniopagus is defined by joining of the 2 skulls at different positions. Typically, the 2 twins are similar in shape and size, but very occasionally one can regress or grow less during intrauterine development, and the remnant of the resorbed twin may remain attached to the main twin as a parasitic twin. ${ }^{9}$

\section{Classification}

Craniopagus is categorized as partial or total, according to the extent of attachment between the twins and the loca- tion of major dural sinuses relative to the conjoined part. The common feature for all phenotypic subgroups of total craniopagus is a shared venous system, and in very complicated cases this may prevent separation. ${ }^{2,17}$ Craniopagus has been subclassified as frontal, parietal, temporoparietal, and occipital. ${ }^{3}$ In addition to this subclassification, further subcategorization has been suggested according to the degree of rotation of one head relative to the other. ${ }^{2}$ Our case was classified as partial angular frontal craniopagus.

Divergent craniopagus types associated with the original abnormalities of the nervous system at the conjoined part and the abnormal vascular anatomy, especially dural sinus anatomy, determine the different risks associated with their surgical intervention. ${ }^{17}$

\section{Approach}

The rational and commonly accepted approach to these patients is to give time to the neonates to be supported by the neonatology team and to postpone surgical intervention until appropriate investigations for other associated anomalies, extensive imaging studies, and models can be completed. During this several-month period, the twins will grow and gain weight, allowing them to better tolerate complex surgery with major anesthetic challenges. ${ }^{3,15-17}$ This time period also allows for the development of a multidisciplinary management team, which is important for an optimal outcome. 

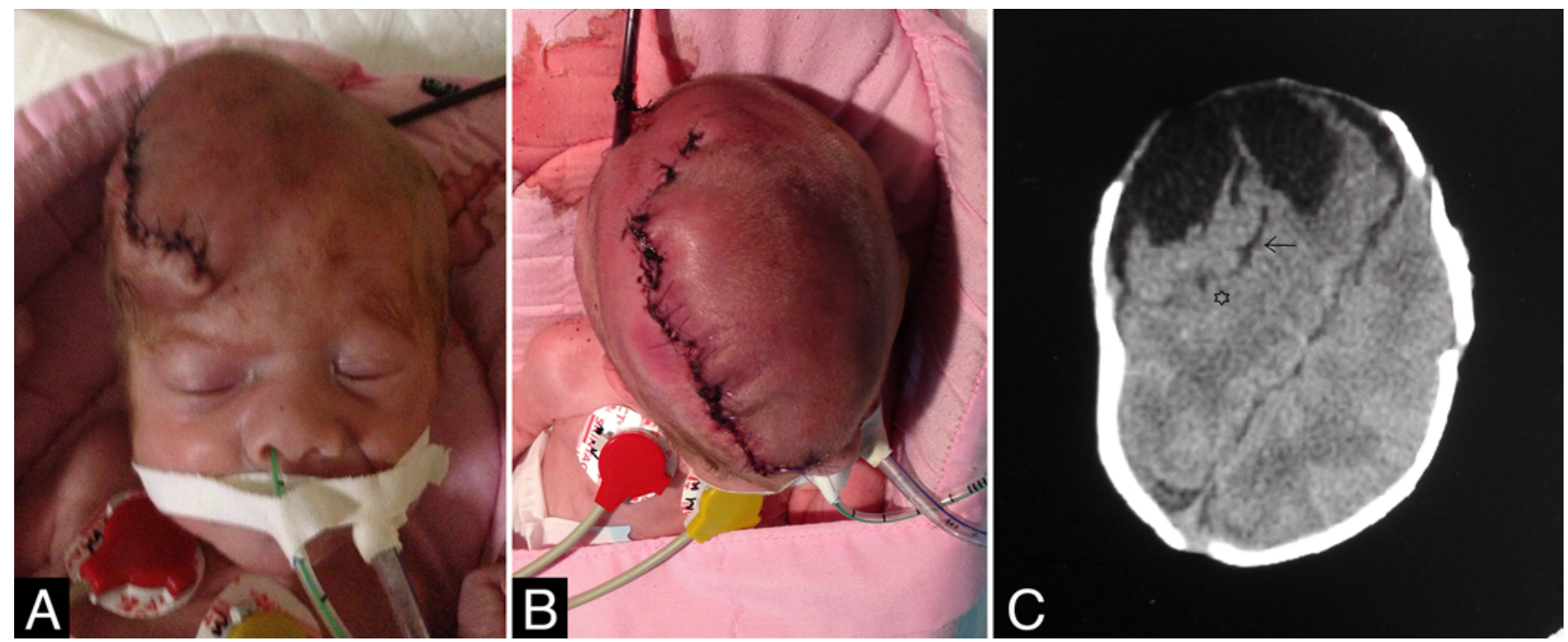

FIG. 5. A and B: Postoperative photographs of the living twin obtained 2 days after the separation operation demonstrating the surgical wound and swelling under the skin. C: CT axial image obtained 2 weeks after surgery showing the shared area of the 2 brains. Some parts of the dead twin's brain are attached to the living twin's brain. The 2 brains were attached to each other with an intact border in one part (arrow) and fused together in another part (star). Figure is available in color online only.

When the neonates are medically stable, simple imaging studies, including brain MRI and CT, can be performed to define the brain anatomy and the vascular system, especially the venous anatomy.

Surgical separation during the first months after birth is associated with more morbidity and greater risk of death due to the twins' very young age and low weight, and the risks are also much greater if the operation is performed on an emergency basis. In almost all of the reported cases of craniopagus in which surgical separation was undertaken during the neonatal period, the twins died. ${ }^{3,4}$ Operating on a premature infant presents additional risk.

In our case, the gestational age of 32 weeks and weight of $1250 \mathrm{~g}$-as well as the lack of an extensive preoperative investigation defining the brain and venous vasculaturewere the most daunting issues with respect to surgical intervention.

\section{Imaging}

In addition to the preliminary imaging performed in the first weeks of life, more extensive investigation is needed before surgical separation. A high-resolution CT scan of the head with fine cuts is performed, and 3D reconstruction of the CT data is necessary to evaluate the extent of bone fusion. High-resolution CT angiography provides good information related to vascularity in the conjoined area. ${ }^{2,3}$ Brain MRI affords detailed information concerning brain anatomy and development, including the shared cortex, the venous sinuses, ventricular system, dural anatomical details, and any associated anomalies. In addition to detailed anatomical information, MRI with arterial and venous MR angiography can increase our knowledge of the vascular system of the brain, especially in shared areas. Functional MRI is a noninvasive tool used in older children or adult twins to define hemispheric language dominance and to guide surgical planning. Selective digi- tal subtraction angiography under good anesthesia can clarify the vascular anatomy accurately and complete the preoperative information and planning., ${ }^{2,-7,12}$ Preparing an acrylic 3D model from CT and MRI data helps the surgical team to have better spatial visualization of all components within the conjoined area for surgical planning. A navigation system that incorporates all CT, MRI, and angiographic data can also increase the power of surgical planning. ${ }^{15}$

In our case, due to the emergency setting of the live twin's attachment to a dead body, we could only perform brain $\mathrm{CT}$ and $\mathrm{CT}$ angiography with $3 \mathrm{D}$ reconstruction to guide surgical planning. The twins' previous brain MRI was not high quality but at least helped us to see the major venous sinuses and be confident that the living twin had independent venous drainage.

\section{Surgical Intervention}

The first successful separation of craniopagus twins was performed by Oscar Sugar in 1952-1953 with staged surgery. Since then, many surgical interventions have been undertaken. As every craniopagus case is unique, different results from no surgical intervention (i.e., conservative management) to successful separation with good followup or intraoperative/postoperative death of one or both twins during one-stage or staged separation have been reported. ${ }^{1-9,11,13,14,17,18}$

A comprehensive anatomical evaluation of the children, a well-equipped multidisciplinary management team (surgical, anesthetic, and medical) that addresses all ethical and philosophical issues of this rare and complex surgery, and parental participation are necessary for surgical management of conjoined twins. ${ }^{8,15}$

This complex surgery includes separation and reconstruction at different anatomical levels of the scalp, skull, dura mater, vascular system, and brain parenchyma. 
Staged separation has been suggested in most cases to decrease the risk of morbidity and mortality. In spite of all preparations suggested for this surgery, the mortality rate has been reported to be around $50 \%$. Review of the literature shows that this surgery is associated with different concerns that affect the result of surgery. These variables include severe intraoperative hemorrhage, intraoperative or postoperative cerebral edema, venous infarct, CSF leakage, meningitis, and brain exposure..$^{10,14,15}$

Most reported craniopagus twins were operated on in an elective setting. In the case of death of one twin, however, the procedure must be performed on an emergency basis because the life of the surviving twin will be seriously threatened. Vascular conjunction at the shared area facilitates the transfer of toxic materials to the circulatory system of the living twin; metabolic disturbances or coagulopathy, especially disseminated intravascular coagulation, may subsequently develop in the surviving twin. Emergency separation, in spite of all reported disadvantages, is essential in this situation to prevent coagulopathy and related lethal complications. ${ }^{11}$ Emergency separation brings worse surgical results than elective surgery due to the poor general condition of the patients, lack of sufficient preparation for this complex procedure, and lack of access to all required members of a multidisciplinary team..$^{10,11}$

In the case presented in this paper, emergency surgery was performed due to the uncomplicated condition of the living twin in an effort to prevent the probable complications of his being attached to the dead one, with mutual vascular circulation at conjoined parts confirmed by CT angiography and MRI. The disadvantages of surgery in this case were the emergency status, the neonate's low weight of only $1250 \mathrm{~g}$, the very young age (gestational age of 32 weeks), and attachment to a dead body with the associated disturbing odor. The most important factors that helped us in successful separation included preoperative blood transfusion during transport to correct the patient's hemoglobin level; fast but delicate surgery with 3 neurosurgeons to decrease intraoperative blood loss; presence of an expert pediatric anesthesiologist; the fact that the craniopagus was partial; absence of major sinus involvement; performance of the separation and reconstruction step by step; use of the dura mater and skin of the shared area for reconstruction (which decreased the time needed for reconstruction); and the stable medical condition of the surviving twin, despite the passage of several hours since the other twin's death.

\section{Outcome}

Partial craniopagus is associated with a better outcome after separation than total craniopagus (with mortality rates of $14 \%$ and $48 \%$, respectively). ${ }^{15}$ Staged surgery, performing an elective procedure when the twins have attained an acceptable age and weight, and less venous structure involvement are the other positive prognostic factors. ${ }^{1,2,14,18}$ Good support from a multidisciplinary team is crucial during the postoperative period to improve the patients' chance of survival, and close follow-up is necessary to detect problems like hydrocephalus and cranial deformity, which are both likely. Due to an abnormal brain or surgical complications, one of the twins will usually have some cognitive or neurological disabilities requiring reha- bilitation. ${ }^{1,15,16}$ In our case, during the first few months of follow-up, we were confronted with a bulging mass (pseudomeningocele) that was intractable to conservative treatment and required shunt placement. The infant has some cranial deformity due to this pseudomeningocele in spite of a well-functioning shunt, and we expect to address this deformity with reconstructive surgery when he is older.

\section{Conclusions}

Comprehensive evaluation of craniopagus twins and the cooperation of a multidisciplinary team are necessary before surgical separation. The operation is performed as an elective surgery except for special circumstances, such as when one of the twins has died, in which case surgical intervention should be done as soon as possible to prevent coagulopathy and related lethal medical complications. Nevertheless, successful separation will still require some knowledge about common vasculature and neural tissue.

Administering perioperative blood transfusion, performing delicate surgery quickly to decrease intraoperative blood loss, and performing the separation and reconstruction step by step are essential measures for better surgical results.

Apart from all disadvantages of emergency separation in the setting of one twin's death, we benefited from some advantages in this case, with the most prominent one being access to enough skin and dura mater from the dead twin to facilitate reconstruction, which is always a challenging issue in such operations. Separation at a younger age gave the parents the opportunity to cope with the situation and to enjoy having an infant with a generally normal shape. The somewhat philosophical view is that the surviving twin was the healthier one, with neither cleft lip nor heart disease. It is a matter of conjecture whether natural selection was at work or whether the afflicted brother sacrificed himself for the healthy one in order to pave the way of life for him by removing a "massive load" from his "head." Whatever view one takes of this situation, it is clear that the mysterious story of craniopagus remains unfinished.

\section{References}

1. Baldwin M, Dekaban A: Cephalopagus twins seven years after separation. Follow-up of a case. J Neurosurg 23:199-203, 1965

2. Browd SR, Goodrich JT, Walker ML: Craniopagus twins. J Neurosurg Pediatr 1:1-20, 2008

3. Bucholz RD, Yoon KW, Shively RE: Temporoparietal craniopagus. Case report and review of the literature. J Neurosurg 66:72-79, 1987

4. Campbell S, Theile R, Stuart G, Cheng E, Sinnott S, Pritchard G, et al: Separation of craniopagus joined at the occiput. Case report. J Neurosurg 97:983-987, 2002

5. Di Rocco C, Caldarelli M, Tamburrini G, Koutzoglou M, Massimi L, Di Rocco F, et al: Craniopagus: the ThessalonikiRome experience. Childs Nerv Syst 20:576-586, 2004

6. Ho YC, Goh KY, Golay X, Hong WT, Lim SH, Pan AB, et al: Functional magnetic resonance imaging in adult craniopagus for presurgical evaluation. J Neurosurg 103:910-916, 2005

7. Jansen O, Mehrabi VA, Sartor K: Neuroradiological findings in adult cranially conjoined twins. Case report. J Neurosurg 89:635-639, 1998

8. Johnson R, Weir P: Separation of craniopagus twins. Camb Q Healthc Ethics 25:38-49, 2016 
9. Kansal R, Kale C, Goel A: Craniopagus parasiticus: a rare case. J Clin Neurosci 17:1351-1352, 2010

10. Kho Uy E, Speranza M, Wong CS: Staged separation of craniopagus conjoined twins: a multidisciplinary approach. AORN J 96:125-151, 2012

11. Owczarek M, Kazmirczuk R, Prokurat A, Chrupek M, SadajOwczarek K, Kusza K: Coagulation changes in a siamese twin in SIRS after death of the other twin: a case study. Med Sci Monit 16:CS1-CS5, 2010

12. Parameswari A, Vakamudi M, Raghupathy V, Siddhartha $\mathrm{R}$ : Anaesthetic management of total craniopagus twins for magnetic resonance imaging and cerebral angiography. Br J Anaesth 105:368-370, 2010

13. Pietrini D, Valenti M, Pusateri A, Scorzoni M, Tosi F, Forte E, et al: Perioperative management of face-to-face craniopagus twins separation. Paediatr Anaesth 15:519-524, 2005

14. Staffenberg DA, Goodrich JT: Separation of craniopagus conjoined twins with a staged approach. J Craniofac Surg 23 (7 Suppl 1):2004-2010, 2012

15. Stone JL, Goodrich JT: The craniopagus malformation: classification and implications for surgical separation. Brain 129:1084-1095, 2006

16. Tannuri AC, Batatinha JA, Velhote MC, Tannuri U: Conjoined twins: twenty years' experience at a reference center in Brazil. Clinics (Sao Paulo) 68:371-377, 2013

17. van Ouwerkerk WJ, van den Berg R, Allison CE, Sibarani R, van Wijk JA, Smit LM, et al: Craniopagus: the Suriname-
Amsterdam conjunction. Childs Nerv Syst 20:625-634, 2004

18. Voris HC, Slaughter WB, Christian JR, Cayia ER: Successful separation of craniopagus twins. J Neurosurg 14:548-560, 1957

\section{Disclosures}

The authors report no conflict of interest concerning the materials or methods used in this study or the findings specified in this paper.

\section{Author Contributions}

Conception and design: Nejat, Habibi, Azad. Acquisition of data: Nejat, Habibi, Goudarzi, Azad, Moradi, Heidari, Kadivar, Soltani. Analysis and interpretation of data: Nejat, Kouchakzadeh. Drafting the article: Nejat. Critically revising the article: Nejat, Habibi, Moradi, Heidari, Kadivar, Soltani. Reviewed submitted version of manuscript: all authors. Approved the final version of the manuscript on behalf of all authors: Nejat. Administrative/technical/material support: Nejat, Habibi, Goudarzi, Azad, Kadivar, Kouchakzadeh. Study supervision: Nejat. Illustration: Soltani.

\section{Correspondence}

Farideh Nejat, Children's Hospital Medical Center, Gharib St., Tehran 14155-7854, Iran. email: nejat@sina.tums.ac.ir. 